\title{
LA PROTECCIÓN DE LOS DERECHOS HUMANOS SOCIALES EN LA SUPERVISIÓN DEL GASTO PÚBLICO DEL GOBIERNO MEXICANO
}

\author{
The protection of social rights in the supervision of \\ public spending by the Mexican government
}

Sergio Arnoldo MORÁN NAVARRO'

Sumario:

I. El Estado Mexicano. II. ¿Qué es democracia? III. Una aproximación a la justicia .IV. Los derechos humanos y su perspectiva. V. La reforma en materia de derechos humanos de 10 de junio de 2011. VI. Los Derechos humanos sociales, una compleja realidad. VII. La falta de transparencia en la supervisión del gasto público como la principal razón de violación de derechos sociales. VIII. A manera de conclusión. IX. Fuentes.

Resumen: La protección de los derechos humanos sociales es uno de los principales objetivos requeridos del Estado constitucional moderno. En este sentido, gran parte de los esfuerzos institucionales deben centrarse para cumplir con esa orden, y en el ejercicio, es posible que el Estado puede proporcionar, la correcta aplicación de los derechos de primera y segunda generación, como el derecho a la vida, a la libertad de sensu lato, la no discriminación y los derechos políticos, entre otros, los resultados favorables, ya que es posible para asegurar su protección la aplicación de los mecanismos que se han implementado en las sociedades modernas para el cumplimiento.

Sin embargo, la protección de los derechos humanos sociales, como la salud, la vivienda, la educación, implica una serie de factores desfavorables que impiden la correcta aplicación, ya que dichos derechos son impulsados por las políticas públicas a través de la acción del Estado, lo que se traduce en la asignación de los recursos públicos destinados al gasto o presupuestos a ejercer por del gobierno. Ante este escenario, el presente estudio determinará que el correcto ejercicio de las asignaciones para la solución de los problemas de derechos sociales, debe significar un compromiso por parte del Estado para cumplir con las libertades mínimas necesarias para el desarrollo de la persona, que es la razón por la monitoreo del gasto público en estas partidas presupuestarias, constituye, la expansión de los derechos sociales.

Palabras clave: Derechos Humanos, Derechos Sociales, Derecho Constitucional.

Abstract: The protection of social human rights is one of the main objectives required of the modern constitutional state. In this regard, much of the institutional efforts should focus to comply with that order, and in the exercise, it is possible that the state can provide, proper

\footnotetext{
${ }^{*}$ Doctor en Derecho por la Universidad Complutense de Madrid, Profesor Titular de la Universidad Autónoma de Nayarit, México, integrante de la Sección Mexicana del Instituto Iberoamericano de Derecho Constitucional, integrante del Sistema Nacional de Investigadores nivel I del Consejo Nacional de Ciencia y Tecnología. Artículo 39 de la Constitución Política de los Estados Unidos Mexicanos
} 
enforcement of the rights of first and second generation, like the right to life, liberty at lato sensu, non-discrimination, and political rights, among others, favorable outcomes, because it is possible to ensure its protection as a result of the mechanisms that have been implemented in modern societies for compliance.

However, the protection of social human rights, such as health, housing, education, involve a number of unfavorable factors that hinder enforcement, because such rights are driven by public policy through State action, which results in the allocation of public resources aimed at expenditure budgets or government spending. Given this scenario, the present study will determine that the proper exercise of the allocations for the solution of the problems of social rights, should signify a commitment by the state to fulfill the minimum liberties required for development of the person, that is why the monitoring of public spending on these budget items, constitute, the expansion of protective of social rights.

Keywords: Human Rights, Social Rights, Constitucional Law.

\section{EL ESTADO MEXICANO}

La composición del Estado mexicano, respecto de su forma de gobierno, y de estado, se sustenta en los artículos 39 y 40 de la Constitución Política de los Estados Unidos Mexicanos. Esta tradición implica, inicialmente, que el principio de la soberanía plasmado en el artículo 39, determina que la "soberanía radica esencial y originalmente en el pueblo", e inclusive al agregar que es el pueblo siempre "tendrá el inalienable derecho de determinar su forma de gobierno".

Aunado a lo anterior, el artículo 40 señala expresamente, que el Estado mexicano tendrá una "forma de gobierno republicano, democrático, representativo, laico y federal", ${ }^{3}$ expresión que respecto a los tres primeros conceptos son adecuados porque se refieren básicamente a la forma de gobierno, pero erróneo respecto del último de estos, ya que lo federal conlleva la determinación de una forma de Estado, más que de gobierno.

Bajo el esquema descrito por Montesquieu en su obra el Espíritu de las leyes, el Estado mexicano plasmó la división del poder en el artículo 49 del mismo texto fundamental, que señala "El supremo Poder de la Federación se divide para su ejercicio en Legislativo, ejecutivo y judicial”. Principio fundamental que se encuentra consagrado desde el siglo XVII y hasta nuestros días, con la prohibición de que "No podrán reunirse dos o más de estos poderes en una sola persona, ni depositarse en legislativo en un individuo". A excepción de los casos extraordinarios que expresamente señala el mismo precepto. ${ }^{4}$

Así, la tradición mexicana ha distribuido la soberanía del estado en diferentes órdenes y niveles de gobierno que han conservado la forma de gobierno descrita en el artículo 40, en los diferentes órdenes de gobierno, bien sea de las entidades federativas o del municipio.

Es de resaltarse también que, la composición que deben tener las entidades federativas respecto del pacto federal, ya que conforme al artículo 41 de la propia constitución federal, el

\footnotetext{
${ }^{2}$ Artículo 39 de la Constitución Política de los Estados Unidos Mexicanos.

${ }^{3}$ El pasado 30 de noviembre del año 2012, se publicó en el Diario Oficial de la Federación, el decreto de reformó a la constitución e incorporó el carácter laico del Estado mexicano.

${ }^{4}$ Y que se refieren sobre todo a la suspensión de garantías de acuerdo con el artículo 29 y los casos excepcionales previstos en el artículo 131 de la Carta Magna respecto al establecimiento de los aranceles respecto de las exportaciones e importaciones de productos.
} 
pueblo estará facultado para ejercer su soberanía a través de los poderes de la unión y de las entidades federativas, ahora a través del Instituto Nacional Electoral, que viene a suplir las competencias que venían ejerciendo tanto el importante Instituto Federal Electoral, como aquellos que tenían instalados los institutos estatales de cada una de las entidades federativas, en lo que respecta a las competencias que ejercen cada uno de ellos, y que en ningún caso podrán contravenir las disposiciones del pacto federal, es decir las disposiciones previstas en la Constitución general, por lo que, a pesar de las disposiciones previstas en las constituciones de las entidades federativas en México, lo cierto es que, la nueva realidad, además de sentar las bases para el ejercicio del principio democrático, es a través de este Instituto Nacional Electoral, 5 que el Estado mexicano se encargará de organizar las elecciones para la renovación de los poderes, no sólo de la Unión, entendido estos como los de la federación, sino de todas las entidades federativas.

En este sentido, el Estado mexicano refuerza en el aspecto constitucional la concepción del principio democrático, al establecer desde la formación de sus individuos a través de la educación el fomento de este principio y definir en el artículo $3^{\circ}$ que II. El criterio que orientará a esa educación se basará en los resultados del progreso científico, luchará contra la ignorancia y sus efectos, las servidumbres, los fanatismos y los prejuicios.

Además: a) Será democrático, considerando a la democracia no solamente como una estructura jurídica y un régimen político, sino como un sistema de vida fundado en el constante mejoramiento económico, social y cultural del pueblo;

A pesar del esfuerzo realizado por los integrantes del Constituyente originario y permanente de consolidar las bases del Estado democrático mexicano, es de observarse, que esta pretensión de fomentar la educación democrática está lejos de aproximarse a alguna de las definiciones tradicionales de los estudiosos del tema, pero la preocupación aumenta cuando la Suprema Corte de Justicia de la Nación ha decidido guardar silencio en la facultad que tiene de manera exclusiva de interpretar la Constitución, ${ }^{6}$ ya que no existe todavía hasta la fecha, interpretación alguna que permita concebir una definición de democracia más acorde con su verdadero significado.

Respecto a las bases de las entidades federativas, a través del pacto federal se establecen las condiciones bajo las cuales deben regularse los estados de la República, consagradas en los artículos 115 y 116 de la Constitución política de los Estados Unidos Mexicanos, al decir del primero, que las entidades federativas "adoptarán para su régimen interior, la forma de gobierno republicano, representativa y popular, teniendo como base de su división territorial y de su organización política y administrativa el municipio libre".

También el artículo 116 determina que "el poder público de los estados se dividirá para su ejercicio, en legislativo, ejecutivo y judicial, con la misma reserva respecto a la concentración de las funciones, que prohíbe expresamente la posibilidad de que "no podrán reunirse dos o

5 El pasado 10 de febrero del año 2014, se publicó en el Diario Oficial de la Federación, otra reforma a la Constitución General de la República Mexicana, mediante el cual, se crea el Instituto Nacional Electoral, organismo que se encargará de organizar todas las elecciones en el Estado mexicano.

${ }^{6}$ Cuestión ya expuesta en la ponencia que presenté en el VIII Congreso Mundial de Derecho Constitucional celebrado del 6 al 10 de diciembre del año 2010. 
más poderes en una sola persona o corporación, ni depositarse el legislativo en un solo individuo".

La traducción de este escenario, se debe realizar desde el punto de vista de la concepción material del concepto de constitución, al constituir los principios bajo los cuales decide ordenarse el poder, así como las bases para la distribución de competencia.

En estricto sentido, dentro de la concepción federalista del Estado mexicano, las entidades federativas no constituyen entidades con plenitud de soberanía, sino que se encuentran delimitadas respecto a las disposiciones que se encuentran consagradas en el pacto federal, es decir, dentro de la propia constitución federal, así como ejerciendo su funcionamiento en base a las facultades implícitas previstas en el artículo 124 de la CPEUM, que prevé que todas las facultades que no se encuentren expresamente concedidas a la federación, se entiende que están reservadas a los estados de la República.

\section{II. ¿QUÉ ES DEMOCRACIA?}

Entrar al estudio de la democracia, la justicia y los derechos humanos, conlleva consigo una responsabilidad histórica. Desde los orígenes de la humanidad, la sociedad ha pretendido garantizar su convivencia mediante la implementación de reglas justas, que reflejen en su resultado una determinación ajustada a los principios más básicos de toda persona.

La democracia, que en opinión de Aristóteles privilegiaron los griegos para determinar el rumbo de sus pueblos, fue el reflejo de una forma de gobierno que ha logrado hoy en día, establecerse al grado que, no es posible concebir un Estado que no sea democrático. Es decir, toda sociedad que se considere civilizada debe contener como forma de gobierno la democracia.

Sin embargo, a pesar de esta exigencia en el ejercicio democrático, no es posible llevarla a todos los ámbitos de la esfera gubernamental, ya que la participación de todos los ciudadanos de una sociedad, en todas las decisiones trascendentales de su gobierno, es en la práctica, imposible de ejercerse.

En este sentido, desde finales de la edad media, John Locke, ${ }^{7}$ proponía una de las clases de democracia que en su concepción, permitiría el ejercicio adecuado del gobierno, ya que llegó a afirmar, que el pueblo común, no tendría el tiempo necesario para poder intervenir en todas las decisiones importancias de su nación. Es por eso que recomendaba la implementación de un modelo de democracia que se llegó a conocer como representativa; consistente en delegar en representantes, la facultad de tomar decisiones que nos vendrían a afectar a todos los integrantes de nuestra sociedad.

A raíz de estas ideas, desde finales del siglo XVIII (en Francia) y hasta nuestros días, a través del principio de soberanía popular que logró consolidar Rousseau, ${ }^{8}$ la mayoría de las naciones empezaron a privilegiar la participación ciudadana como uno de los principios básicos de toda sociedad que se considerara civilizada.

Recordemos que a inicios del siglo XX, las sociedades democráticas se pusieron en crisis por los regímenes totalitarios, como lo fueron los gobiernos nazistas y fascistas, por citar algunos ejemplos. Sin embargo, al término de la segunda guerra mundial, la participación

\footnotetext{
7 Para mayor abundancia, cfr. LOCKE, John, Ensayo sobre el gobierno civil, ed. Porrúa, México, 2003.

8 A través de su obra cumbre ROUSSEAU, Jean Jacques, El contrato social, ed. Porrúa, México, 2006. 
ciudadana en la toma de decisiones, se consolidó en la mayoría de las naciones del mundo moderno.

Para considerar un ejercicio adecuado de democracia, es necesario que los individuos que participan en ella, tengan satisfechas, las necesidades elementales para su subsistencia, ya que de no ser así, factores externos incidirán gravemente en la vulneración de su libertad individual.

Ya que el hambre, la salud e inclusive, la falta de educación, pueden generar una voluntad viciada que responda de manera errónea a satisfacer sus necesidades en vez de pensar en las decisiones que pudieran tener una mayor relevancia para toda la sociedad. A tal grado llega esta condición, que inclusive en el último estudio sobre la democracia en América Latina,9 gran porcentaje de los encuestados prefirieron elegir desarrollo que democracia.

\section{UNA APROXIMACIÓN A LA JUSTICIA}

La concepción de justicia tiene una justificación distinta a la de democracia, de hecho, es posible hablar de justicia sin democracia, y podemos plantearnos también a contrario sensu esta cuestión. Desde la antigüedad, es posible concebir lo que se considera como justo, en el Derecho romano, podemos encontrar una concepción que básicamente es válida en nuestro tiempo: dice Justiniano que la justicia "Es el arte de dar lo justo y hacer lo justo a un individuo, basándose en los principios del arte del Derecho, sin tener ningún tipo de discriminación o preferencia hacia ninguna persona" y enfatiza "Ya que todas las personas deben ser tratadas sin ninguna discriminación o preferencia ya que así se estaría dando una justicia falsa y no sería dar a cada uno lo suyo sino dar a él lo que le toque dependiendo de su clase social o raza". Todavía el jurista Ulpiano consideró a la justicia como la constante y perpetua voluntad de dar a cada quien lo suyo, es decir el Derecho". ${ }^{10}$

Siguiendo este orden, autores como Perelman $\mathrm{Chaim}^{11}$ han definido a la justicia como el principio de acción de acuerdo con el cual los seres de una misma categoría esencial deben ser tratados de la misma manera"; si nos detenemos un momento en esta definición, es posible percatarnos que la aplicación de la justicia supone una distinción a partir de lo que se considera esencial en cada ser humano.

Si precisamos esta característica, encontramos que las grandes diferencias de la humanidad se han basado históricamente en cuestiones de raza, género y religión. Ya que con fre-

\footnotetext{
${ }^{9}$ Cfr. NOHLEN Dieter, El contexto hace la diferencia: reformas institucionales y el enfoque histórico empírico, IIJ UNAM y Tribunal Electoral del Poder Judicial de la Federación, México, 2003, pp. 136 y ss.

${ }^{10}$ GONZÁLEZ DE LA VEGA, Rene, Justicia e ideología. Libro electrónico (2008) IIJ-UNAM, p. 1.

${ }^{11}$ PERELMAN CHAIM, De la justicia, Centro de Estudios Filosóficos, UNAM, libro electrónico IIJ UNAM (2008), http://www.bibliojuridica.org/libros/libro.htm?l=453, Primera Edición en español 1964, pp. 43 y ss.
} 
cuencia, el ser humano ha distinguido a quienes se le asemejan, provocando una alternación de lo justo en aquellos que no son semejantes.

El principio de igualdad como vemos, va ligado al de justicia, a tal grado, que las personas deben tratar a sus semejantes como iguales, y en esta medida esencial deberán ejercer su función. ${ }^{12}$

Para Kelsen, el problema de la justicia surge cuando hay un conflicto de intereses, y tales conflictos solo pueden ser resueltos en base a una concepción subjetiva por un individuo, y de acuerdo a un juicio de valor relativo a lo que ese sujeto estime como valor supremo. ${ }^{13}$

En este sentido Recasens, afirma que uno de los principios que puede propiciar una mejor decisión es la tolerancia, ya que en base a esta, diversos valores contenidos en una sociedad, va a propiciar que se conozcan las diferentes características que componen a todos y cada uno de los individuos de la sociedad.

Sin embargo, toda esta argumentación que ha girado en torno al principio de justicia, evolucionó a un nivel insospechado cuando John Rawls, publicó su obra la teoría de la justicia, al considerar a esta sobre todo, como una característica que deberían tener todas las instituciones sociales, y afirmar "Las instituciones básicas de la sociedad no deben distinguirse simplemente por ser ordenadas y eficientes: ellas deben ser, sobre todo, justas. Y si no lo son, deben ser reformadas o abolidas". ${ }^{14}$

Pero al respecto, Rawls condiciona la obtención de estos fines a dos aspectos a considerar. El primero de ellos, se basa en la composición del individuo, al afirmar: "cada individuo a de tener un derecho igual al esquema más extenso de libertades básicas iguales que sea compatible con un esquema semejante de libertades (civiles y políticas) para los demás. Y segundo enfocado más al aspecto del entorno al decir "las desigualdades sociales y económicas habrán de ser conformadas de modo tal que a la vez que: a) se espere razonablemente que sean ventajosas para todos, $b$ ) se vinculen a empleos y cargos asequibles para todos."

En este sentido, Rawls condiciona la justicia, a aquello que cualquier persona pudiera obtener en razón de las pretensiones más amplias posibles. Sin embargo, cuando el individuo se encuentre en un escenario de desigualdad por razones sociales o económicas, el trato no puede traducirse en base a la regla anterior, sino que debe ajustarse atendiendo a estos factores. En términos técnicos, esta concepción se conoce como liberalismo igualitario, que demanda al Estado a solventar igualaciones necesarias a través de sus instituciones. ${ }^{15}$

\section{LOS DERECHOS HUMANOS Y SU PERSPECTIVA}

La concepción de derechos humanos, deriva de la decisión tomada al término de la segunda guerra mundial, en el seno de la Organización de Naciones Unidas, como respuesta a la degradación que sufrió el individuo por las naciones totalitarias (nacistas y fascistas) y que pretendían su aniquilación de personas por razones de raza, genero o religión, que propició la Declaración universal de los derechos humanos en 1948, suscrita por quienes integraron la nueva ONU, y que provocó que cualquier nación que procurara incorporarse, debería

\footnotetext{
${ }^{12}$ GONZÁLEZ DE LA VEGA, Ibidem, p. 3.

${ }^{13}$ Citado por RECASENS SICHES, Luis, Panorama del pensamiento político en el siglo XX, ed. Porrúa, México, 1963, T. I, p. 63.

${ }^{14}$ RAWLS, John, Teoría de la Justicia, ed. Fondo de Cultura Económica, México, 1995.

${ }^{15}$ Citado por GONZÁLEZ DE LA VEGA, Op. Cit.p. 245 y ss. 
asumir la declaración como compromiso ante todos sus ciudadanos y ante la comunidad internacional.

En otros aspectos, esta declaración estableció en su artículo 1, la concepción de ser humano y sus condiciones, al decir "Todos los seres humanos nacen libres e iguales en dignidad y derechos y, dotados como están de razón y conciencia, deben comportarse fraternalmente los unos con los otros". La razón era, evitar la denigración de la especie humana, la generación de condiciones que se deberían observar, tanto por las autoridades como por los ciudadanos, en la convivencia de todos en sociedad.

En opinión de Pedro Nikken, el poder público debe ejercerse al servicio del ser humano, y por lo consecuente, debe afirmarse siempre y en todo momento la dignidad de la persona frente al Estado. ${ }^{16}$ De tal forma, que pude afirmarse que toda persona tiene derechos frente al Estado, y que éste último debe respetar y garantizar esos derechos.

Además, se debe considerar que los derechos humanos no dependen del reconocimiento de cualquier Estado, ni que han sido concesionados por este. Ni depende de cuestiones de nacionalidad, cultura, raza o religión alguna. Y la característica de universal, es porque corresponde a cualquier habitante de la tierra.

Pero, ¿qué derechos se consideran como humanos?, ¿qué aspectos de la vida de las personas debe ser protegida y garantizada contra cualquier actuación del poder público? Históricamente la declaración de independencia de Estados Unidos de 1776, proclamó a la vida, la libertad y la búsqueda de la felicidad como los principales derechos de su sociedad, con la característica que pertenecían a cualquier individuo.

En Francia, en la Declaración de los Derechos del Hombre y del Ciudadano de 1789, se reconoció la característica de que los hombres nacen libres e iguales en derechos, y que las distinciones sociales no pueden estar fundadas sino en la utilidad común. A pesar de que las declaraciones constituyen un acto solemne por medio del cual, quienes los suscriben, proclaman su apoyo a principios de gran valor. Sin embargo, en lo que respecta a las declaraciones de derechos por si mismas, son irrelevantes, debido a que no cuentan con mecanismos de protección que garanticen su vigencia, ya que su cumplimiento ha carecido de valor vinculante desde el punto de vista jurídico, es decir, que se trataba solo de buenas intenciones por los estados que las suscriban.

Hoy en día, encontramos en la opinión general de los doctrinistas basadas en las ideas de Karel Vasak, tres generaciones de derechos humanos. ${ }^{17}$ La primera generación, se basa en el reconocimiento de los derechos civiles y políticos, consistentes en la satisfacción de las necesidades básicas del ser humano, como la vida, la libertad, así como aquellos tendientes a

\footnotetext{
${ }^{16}$ NIKKEN, Pedro, Estudios básicos de derechos humanos, t. I, Ed. Instituto Interamericano de derechos humanos, Primera edición San Jose, 1994, libro electrónico http://www.bibliojuridica.org/libros/libro.htm?l=1835 IIJ UNAM (2008) pp. 15 y ss.

${ }^{17}$ KAREL VASAK, "Human Rights: A Thirty-Year Struggle: the Sustained Efforts to give Force of law to the Universal Declaration of Human Rights”, UNESCO Courier 30:11, Paris: United Nations Educational, Scientific, and Cultural Organization, november 1977.
} 
elegir a sus gobernantes, y que el poder público se encuentra inhibido de entrar en la esfera de estos derechos, por ser estos de naturaleza individual y privada.

La segunda generación, deriva en los derechos económicos, sociales y culturales que se vinculan directamente con el principio de igualdad, y a contrario de los de primera generación, exigen del Estado una actuación a través de los servicios públicos.

También existen los derechos humanos de tercera generación, que se vinculan con aspectos relacionados con la solidaridad, y se incluyen aspectos como la paz mundial, la calidad de vida o la dignidad humana y el medio ambiente. Por último, existen autores que consideran una cuarta generación de derechos humanos, derivado sobre todo de la utilización en la ciencia de nuevas tecnologías, y que tienden a proteger la naturaleza humana, como ejemplo la bioética o la manipulación genética. ${ }^{18}$

\section{LA REFORMA DE 10 DE JUNIO DE 2011 EN MATERIA DE DERECHOS HUMANOS}

Recientemente el Estado mexicano realizó una importante reforma que cambió la concepción de las libertades en nuestra sociedad, así como para proteger las mismas, a través del mecanismo que nos ha permitido posicionarnos en el ámbito internacional, como lo es el juicio de amparo, ya que el pasado 10 de junio del año 2011, se aprobaron dos reformas a la Constitución Política de los Estados Unidos Mexicanos en materia de Amparo y de Derechos Humanos, que pretendieron ampliar la esfera de protección de las libertades del individuo, no sólo cambiando el título primero de la Constitución General, sino incluyendo en los juicios de garantías promovidos a través del juicio de amparo, a la protección de los derechos humanos incluidos en los tratados internacionales que el Estado mexicano ha suscrito. Sin embargo, a pesar de esta importante reforma, los resultados no han sido del todo satisfactorios.

Con esto, el Estado mexicano se ha comprometido con la comunidad internacional, a garantizar el cumplimiento y la vigencia de los derechos humanos dentro del territorio nacional, que si bien es cierto, de entrada, fue adoptada por la sociedad mexicana con una gran expectación, lo cierto es también, que en la doctrina debe significarnos una preocupación no menor, que exigirá por parte del Estado mexicano de todo su esfuerzo para garantizar su cumplimiento.

La reforma de referencia, cambió de fondo, no sólo la noción tradicional que se tenía en el Estado mexicano de las libertades de las personas, como se les denominaba, es decir, las garantías individuales, que durante casi un siglo tuvo una vigencia inalterable al paso del tiempo, sino que también modificó substancialmente la concepción de derechos que se podrán proteger, debido a que en los sistemas iuspositivistas, la concepción utilizada se

\footnotetext{
${ }^{18}$ VALLESPÍN PÉREZ, David, El modelo constitucional de juicio justo en el ámbito del proceso civil. Barcelona, 2002 , p. 31. 
sustenta en la noción de derechos fundamentales, ${ }^{19}$ más que en la de derechos humanos, ${ }^{20} \mathrm{y}$ este no es un problema menor;

Esta expectativa, fue aún mayor, cuando se habilitó a uno de los mecanismos tradicionales dentro de la tradición mexicana, y que constituye sin dudarlo un referente en el ámbito internacional, como lo es el Juicio de Amparo, debido a que, dentro de la adecuación del marco normativo, se expidió una nueva Ley de Amparo, ${ }^{21}$ la cual, además de proteger aquella concepción que se tenía en el Estado mexicano para proteger las garantías individuales, que más que éstas se concebían en la noción más consolidada de la doctrina internacional como derechos fundamentales, ahora es protector también de los derechos humanos, bien sea que, se encuentren reconocidos en la Constitución General o en los diversos tratados internacional aprobados por el Estado mexicano.

Debemos entender también que, entre otras cuestiones que representarán sin duda un nuevo paradigma de la protección de los derechos fundamentales, la reforma de 10 de junio de 2011, conlleva una serie de modificaciones que requerirán un amplio esfuerzo de las instituciones del Estado mexicano en todos sus niveles y órdenes de gobierno, ya que, como es sabido por todos, la concepción federalista inmersa en la forma de estado mexicano, requiere de un alineamiento de los poderes y órdenes de gobierno en todos sus ámbitos, ya sea federal, estatal y municipal.

Cuestión no menor a realizar, debido a las diferentes ideologías de quienes ejercen el poder en cada una de las entidades del país, y más compleja aún, si se pretende operar en el ámbito municipal, por la limitada composición organizativa y la escasez presupuestal asignada a los ayuntamientos, cuestión que exponencialmente se aumenta con la escasa formación educativa de quienes desempeñan labores fundamentales en ejercicio de una función pública en este orden de gobierno.

Este escenario complejo, ha sido debidamente delimitado por Miguel Carbonell y Eduardo Ferrer Mac-Gregor recientemente, ${ }^{22}$ y sin dudarlo, la forma de estado Federal en esta nueva realidad, va a ser exigida con creces para dar cumplimiento a las nuevas condiciones que derivan de la materia de derechos humanos, máxime, porque las nuevas condiciones del artículo 1 de la Constitución Política de los Estados Unidos Mexicanos han cambiado, y el llevar a la práctica lo plasmado por el constituyente permanente, no será tarea fácil.

\footnotetext{
${ }^{19}$ Sobre los derechos fundamentales cfr. ALEXY, Robert, Teoría de los Derechos Fundamentales, ed. Centro de Estudios Políticos y Constitucionales, Madrid 1993; también FERRAJOLI, Luigui, Los Fundamentos de los Derechos Fundamentales, editorial Trotta, Madrid, 2001; véase también CARBONELL, Miguel, Los derechos fundamentales en México, Cuarta Edición, ed. UNAM-CNDH, México 2011.

${ }^{20}$ Sobre los Derechos Humanos, cfr. DWORKIN, Ronald, Los Derechos en serio, editorial Ariel, Barcelona, 1984; también CARPIZO, Jorge, Los Derechos Humanos: naturaleza, denominación y características, en Revista Mexicana de Derecho Constitucional, número 25 julio-diciembre 2011, p. 4 y ss.

${ }^{21}$ Publicada en el Diario Oficial de la Federación el pasado 2 de abril del año 2013.

22 CARBONELL, Miguel, Las obligaciones del Estado en el artículo $1^{\circ}$ de la Constitución Mexicana y Ferrer Mac-Gregor, Eduardo, Interpretación conforme y control difuso de convencionalidad, ambas colaboraciones publicadas en la obra La reforma Constitucional en Derechos Humanos: un nuevo paradigma, Coordinada por Miguel Carbonell y Pedro Salazar, ed. IIJ-UNAM, México 2011, p. 358 y ss.
} 


\section{EL PANORAMA DE LOS DERECHOS SOCIALES, UNA TRAYECTORIA DISTINTA}

En la doctrina, el panorama de los derechos humanos de tercera generación, ha sido desalentador. ${ }^{23}$ En opinión de Abramovich, Víctor y Courtis Christian, los derechos sociales se caracterizan, como meras declaraciones de buenas intenciones, de compromisos políticos, o en el peor de los casos, de engaño o fraude tranquilizador. ${ }^{24}$ En este sentido, inclusive, tanto los textos constitucionales como las normas internacionales que establecen derechos sociales, ${ }^{25}$ son considerados como documentos de carácter político, antes que catálogos de obligaciones jurídicas para el Estado.

A pesar de los problemas que conllevan consigo los derechos sociales, lo cierto es, que a diferencia de los derechos civiles y políticos que requieren de una actitud pasiva del Estado para no vulnerarlos, como pudiera ser el no realizar detenciones arbitrarias, no condenar a una persona sin un juicio justo, no restringir la libertad de expresión, ni violar la propiedad privada, por citar algunos, en el caso de los derechos económicos, sociales y culturales el Estado de una actuación positiva, es decir, necesita de un hacer, de realizar una actitud activa, como pudiera ser el de proveer instituciones de salud, educación, fomentar la cultura y conservar el patrimonio cultural, entre otras cuestiones. ${ }^{26}$

Es decir, para la protección, salvaguarda o garantía de los derechos de tercera generación, no basta sólo con que el Estado instaure un orden jurídico, ni de la sola decisión política de los órganos gubernamentales, sino de un orden social donde impere la justa distribución de los bienes, ${ }^{27}$ el cual sólo puede alcanzarse de manera progresiva mediante la implementación de políticas públicas que impacten favorablemente en los sectores de la población a la cual van destinadas.

Es decir, para que el Estado se encuentre en condiciones de cumplir con los compromisos que derivan los derechos sociales, es menester que, el Estado destine de forma inmediata la erogación de recursos económicos. ${ }^{28}$ Ya que, en opinión de Contreras Peláez, la prestación del Estado representa sustancialmente el núcleo, el contenido esencial del derecho, debido a que, en casos como la asistencia sanitaria o la educación gratuita, la intervención estatal tiene lugar en todas y cada una de las veces que el derecho es ejercitado, de tal suerte que,

\footnotetext{
${ }^{23}$ EIDE, A., "Future Protection of Economic and Social Rights in Europe" en A. Bloed et al (eds.) Monitoring Human Rights in Europe: Comparing International Procedures and Mechanisms, Dordrecht-Boston-Londres, 1993 p. 187-219; G. H. J. Van Hoof, “The Legal Nature of Economic, Social and Cultural Rights: A Rebuttal of Some Traditional Views" en P. Alston y K. Tomâsevski (eds.) The Right of Food, Utrecht, 1984; P. Alston, "No Night to Complain About Being Poor: The Need for an Optional Protocol to the Economic Rights Covenant" en A. Eide y J. Helgesen (eds.) The Future of Human Rights Protection in a Changing World, 1991.

${ }^{24}$ ABRAMOVICH, Víctor y COURTIS, Christian, en Los derechos sociales como derechos exigibles, ed. Trotta, segunda edición, Madrid, 2004, p. 19.

${ }^{25}$ Como lo es el Pacto Internacional de Derechos Económicos, Sociales y Culturales, adoptado por la Asamblea General de Naciones Unidas en su resolución 2.200 (XX), el 16 de diciembre de 1966, firmado el 19 de diciembre del mismo año y entrado en vigor el 3 de enero de 1976.

${ }^{26}$ Ibídem, p. 21 y ss.

${ }^{27}$ GARRETÓN MERINO, “La sociedad civil como agente de promoción de los derechos económicos, sociales y culturales" en IIDH, estudios básicos de derechos humanos V, San José de Costa Rica, 1996, p. 59

${ }^{28}$ R. BIN, "Diritti e fraintendimenti”: Ragion Pratica, 14, 2000, p. 14 y ss; al respecto, también cfr. S. Holmes y C.R. Sunstein, The Cost of Rights-Why Liberty Depends on Taxes, Nueva York- Londres, 1999; también, C. Fabre, Social Rights under the Constitution, ed. Oxford, 20oo, p. 44 y ss.
} 
ante la ineficacia de la prestación del servicio, conlleva automáticamente la denegación del derecho. ${ }^{29}$

En este sentido, la relevancia de los derechos sociales, subsiste en la medida misma en que el Estado pueda cumplir, de forma continua e ininterrumpida, con el servicio, bien sea en el aspecto de la salud o de la educación, por citar algunos ejemplos, que requerirá en cada caso, de la asignación de recursos económicos suficientes para cumplir con los fines y objetivos que se tiene previsto realizar.

Sin embargo, desde mi óptica personal, este sólo es el problema inicial, debido a que, el Estado mexicano en la actualidad, cumple con la función de destinar recursos públicos para la protección de los derechos sociales en cada uno de los presupuestos que ha autorizado, por lo que, si consideramos solo este aspecto, dejaremos de lado un factor crucial para la protección de los derechos sociales, que no es otro que la transparencia en la supervisión del gasto público.

VII. LA FALTA DE TRANSPARENCIA EN LA SUPERVISIÓN DEL GASTO PÚBLICO COMO LA PRINCIPAL RAZÓN DE VIOLACIÓN DE DERECHOS SOCIALES

Uno de los aspectos fundamentales en la concepción del Estado moderno, es la inclusión del principio democrático, de tal suerte que, quien resulta triunfador en las elecciones, está facultado para decidir el futuro de la nación, mediante las acciones de gobierno que derivan de la voluntad mayoritaria que los eligió. ${ }^{30}$

En este sentido, la democratización de una sociedad, recae en los mecanismos de control que se ejercen sobre el gobierno, debido a que, cuanto más avanzada, compleja y plural sea una sociedad, más necesidad está de contar con instrumentos de control del poder político, porque la esencia de la democracia no reside en el imperio sin límites de la mayoría, ${ }^{31}$ sino en el compromiso histórico entre los diferentes grupos representados en el parlamento de adoptar las mejores decisiones en beneficio de la sociedad.

Recordemos que, en la concepción del Estado moderno, se tuvo una influencia ideológica liberal, que propició la noción más aceptada en sus inicios de la no intervención del Estado en la actividad económica de las naciones, ${ }^{32}$ sin embargo, con el reconocimiento de los derechos sociales, la actitud del Estado no pudo continuar siendo pasiva, sino que requirió de la planificación de los problemas que aquejaban a su sociedad, y satisfacer la concepción del Estado mínimo de bienestar, que vino a transformar los objetivos a alcanzar de la sociedad moderna.

Hoy en día, el control del gasto público ha adquirido dimensiones no previstas en sus orígenes, debido a que, las grandes necesidades del Estado moderno requieren de una amplia cantidad de recursos públicos para satisfacer la demanda de diversas necesidades que se requieren para todos, es decir, para cubrir la amplia cobertura de los derechos sociales, pero debido a la ejecución diaria de estos programas en manos del gobierno, debemos mantener

\footnotetext{
${ }^{29}$ CONTRERAS PELÁEZ, Derechos sociales: teoría e idelología, Madrid 1994, p. 21 y ss.

${ }^{30}$ KELSEN, Hans, Foundations of Democracy, Ethics, LXVI (Escritos sobre la democracia y el socialismo), traducción de Juan Ruiz Manero, ed. Debate, Madrid, 1995, p. 207 y ss.

${ }^{31}$ PÉREZ ROYO, Javier, "El Tribunal de Cuentas en la Constitución y en el proyecto de ley reguladora del mismo" en El Tribunal de Cuentas en España, Vol. II, Instituto de Estudios Fiscales, Madrid, 1982, p. 1145 y ss.

${ }^{32}$ FORSTHOFF, Ernst, "Problemas constitucionales del Estado social” y "Concepto y esencia del Estado Social de Derecho” en El Estado Social”, ed. Centro de Estudios Constituconales, Madrid, 1986.
} 
la alerta sobre dichos recursos, porque históricamente nuestra sociedad se ha visto seriamente afectada por los abusos o excesos en el ejercicio del poder público. ${ }^{33}$

Lo cierto es que, en el ejercicio del poder, no se requiere únicamente que el parlamento dé el visto bueno a la propuesta del ejecutivo de su programa de gobierno. Para Aragón Reyes, en el control político se requiere no sólo de un control formal de autorización previa a la ejecución material de la obra a realizar, tanto en los sistemas presidencialistas, como en los parlamentarios, sino de asegurar que los recursos autorizados para tal objetivo, sean ejercidos adecuadamente. A tal grado que, debe analizarse si se cumplieron los fines previstos, y en caso contrario, discutir las medidas a adoptar. ${ }^{34}$

En este sentido, el papel que juega el parlamento en el Estado democrático, no sólo consiste en aprobar el presupuesto que asignará al ejecutivo para sus programas de gobierno, sino también, en supervisar cómo realizó el gasto público. Y para conseguirlo, deberían asegurarse los mecanismos adecuados para ejercer un control adecuado y completo. ${ }^{35}$ Este camino trazado, tradicionalmente, en opinión de Chubb, termina en que el parlamento deber ejercer una función fiscalizadora o investigadora, no sólo para supervisar el destino de los recursos públicos recaudados a través de los impuestos, sino también que éstos sean gastados conforme lo autorizó el parlamento. ${ }^{36}$ De tal forma que, bajo la concepción de la teoría de los frenos y contrapesos, en opinión de Orlando, el ejecutivo solicita la aprobación del proyecto de ley de presupuesto, priorizando las partidas presupuestarias que conformarán el gasto público, y en caso de considerarlo adecuado, el legislativo aprobará el presupuesto a ejercer. ${ }^{37}$

Así, hoy en día se constituyen dos modelos a seguir en el control del gasto público externo. Por un lado, existe el modelo jurisdiccional francés, y por otro el modelo parlamentario inglés. En lo que respecta al primero, ha logrado tener un impacto en los países que integran la Unión Europea, de tal forma que, los Tribunales de Cuentas se constituyen como una referencia por su eficacia y profesionalismo en la supervisión del gasto $; 3^{8}$ por su parte, el segundo modelo, tuvo una amplia influencia en los países que derivan de la tradición inglesa, como lo han sido Canadá y los Estados Unidos de América, y por la cercanía a este último, nuestra nación México, también lo ha adoptado. ${ }^{39}$

Con independencia del modelo a seguir, cualquiera de las instituciones que se creen para la supervisión del gasto, el orden constitucional y legal debe garantizar, de forma rotunda y contundente, su independencia, organización y funcionamiento interno con profesionalis-

\footnotetext{
${ }^{33} \mathrm{Al}$ respecto, bastante literatura se ha escrito en este sentido, como lo han sido las obras de Montesquieu, L'Espirit des Lois, Libro XI, capítulo 6; Madison, Federalist, The size and variety of the Union as Check on Faction, number 10, y 51 Check and Balance; Tocqueville, Alexis, De la Démocratie en Amérique, La democracia en América, ed. Alianza Editorial, colección Política, primera edición, 2002.

${ }^{34}$ ARAGÓN REYES, Manuel, "Sistema parlamentario, sistema presidencialista y dinámica entre los poderes del Estado. Análisis comparado" en Parlamento y Control del Gobierno. V Jornadas de la Asociación Española de Letrados de Parlamentos, coord.. Francesc Pau I Vall, ed. Aranzadi, Pamplona, 1998, p. 30

${ }^{35}$ BALLS, Herbert R. "The Public Accounts Committee", en Canadian Public Administration, V. 6, 1963, p. 15.

${ }^{36}$ CHUBB, Basil, The Control of Public Expenditure. Financial Committees of the House of Commons, Clarendon Press, Oxford, 1952, p. 6.

${ }^{37}$ ORLANDO, Principii di Diritto Costituzionale, ed. Barbera, 5th ed., Firenze, 1909, p. 143.

${ }^{38}$ ESPERÓN LÁZARO, José Antonio, "El Tribunal de Cuentas de la Comunidad Económica Europea ante los dos modelos de control externo: Francia y Gran Bretaña" en AAVV El Tribunal de Cuentas de las Comunidades Europeas y los Tribunales de Cuentas de los países miembros: competencias y relaciones, Encuentro Internacional, Tribunal de Cuentas, Madrid, 1989, p. 209.

${ }^{39} \mathrm{Al}$ respecto cfr. HARRIS, Joseph P., Congressional Control of Administration, Reprinted by Greenwood Press, Wesport, Connecticut, 1980, p. 4 y ss.
} 
mo y una amplia preparación técnica, con el fin de lograr una administración pública eficaz, eficiente y económica. ${ }^{40}$

En este sentido, en el Estado mexicano, podemos decir que le ha abonado favorablemente para generar las condiciones más propicias respecto a la integración y funcionamiento del órgano encargado de fiscalizar el gasto público. Así lo demuestra la regulación constitucional consagrada en el artículo 79, cuyo contenido se ajusta perfectamente a las condiciones previstas para este órgano, que en nuestra nación se denomina la Entidad de Fiscalización Superior de la Federación. Y respecto a la concepción del modelo federal, las entidades federativas del Estado mexicano replican en los mismos términos la organización y funcionamiento de los entes encargados de supervisar el gasto público.

Aunado a lo anterior, conviene destacar que, recientemente el constituyente permanente realizó otra reforma constitucional al artículo $134,{ }^{41}$ para exigir que, respecto del gasto público, los recursos económicos que dispongan tanto la Federación, como las entidades federativas, los municipios, el Distrito Federal y los órganos político-administrativos de sus demarcaciones territoriales, se administraran con eficiencia, eficacia, economía, transparencia y honradez para satisfacer los objetivos para los cuales fueron destinados.

Robusteciendo aún más el escenario favorable que ha creado el Estado mexicano en esta materia, el pasado 7 de febrero del 2014, se publicó la reforma al artículo $6^{\circ}$, entre otros preceptos, que dota de autonomía a la entidad que se encargará de garantizar el cumplimiento del derecho de acceso a la información pública y a la protección de datos personales en posesión de los sujetos obligados en los términos de ley.

A pesar de lo anterior, lo cierto es, que a la fecha, difícilmente se puede obtener información confiable y veraz que permita comprobar que los principios constitucionales bajo los cuales se sustenta la supervisión del gasto público, es objetiva, y que cumple con los fines para los cuales fueron destinados los recursos públicos.

Si nos preguntamos simplemente, ¿Cuánto es la deuda del Estado mexicano? Posiblemente obtendremos una respuesta inmediata, pero si se pregunta ¿En qué se endeudo el Estado mexicano? La respuesta no será sencilla, mucho menos si llegamos a preguntar ${ }_{¿}$ Ha sido el gasto que ha realizado el Estado mexicano Eficaz, eficiente y se ha sujetado al principio de economía como lo disponen las exigencias del artículo 134 constitucional? y estas dos últimas preguntas, habría que hacerla no sólo de la federación, sino de los diversos niveles u órdenes de gobierno, en cualquiera de los poderes públicos, con resultados muy similares.

VIII. A MANERA DE CONCLUSIÓN

El ejercicio del poder público, implica el reconocimiento de ciertos valores que han sido el resultado de una evolución de la convivencia pacífica de los individuos en sociedad. La

\footnotetext{
${ }^{4^{\circ}}$ En ese sentido cfr. WALKER, Wallace Earl, Changing Organizational Culture, Strategy, Structure and Professionalism in the U.S. General Accounting Office. The University of Tennessee Press, Knoxville, 1986; también Devolve, Pierre et Lesgullons, Henry, Le contrôle parlamentaire sur la politique économique et budgétaire, Presses Universitaires de France, Paris, 1964, p. 10 y ss., Coen, F., "Declino del parlamento ed organizzacione di nuovi centri di potere” en Democrazia e diritto, enero-marzo, 1963. Berettoni, Arleri, L'Ordenamentoed il controllo della spesapubblica in Francia, ed. Giuffré, Milano, 1967; García Morillo, Joaquín, "El parlamento ante las nuevas realidades” en Corts, Anuario de Derecho Parlamentario, número 4, 1997, p. 141 y ss.

${ }^{41}$ Publicada en el Diario Oficial de la Federación el 7 de mayo de 2008.
} 
participación ciudadana en la toma de decisiones, es una forma de gobierno que permite vincular a los individuos de una sociedad, en las esferas más importantes de su vida.

Si el gobierno se ejerce por delegación de todos los individuos a unos cuantos en una sociedad, que en teoría han alcanzado la madurez para la toma de decisiones a través de la ciudadanía, resulta de una trascendental importancia precisar, que este acuerdo para el ejercicio del gobierno ha sido fruto de un acuerdo que todo pueblo está dispuesto a cumplir, y a refrendar en cada uno de sus procesos electorales, y que por lo consecuente forma parte de las reglas básicas de todo Estado democrático.

Existen en otros estados, una forma de hacer corresponsable a la sociedad, implementando mecanismos de participación ciudadana, sin embargo, para llegar de manera adecuada a los mismos, se requiere de que los individuos a nivel social, tengan cubiertas las necesidades más básicas para generar las garantías suficientes para el ejercicio adecuado y esta responsabilidad social.

Con la finalidad de resolver las diferencias que surgen de la convivencia social, los individuos han decidido delegar en un ser superior en fuerza, como lo es el Estado, la decisión última que deberá acatarse. Pero a pesar de esa superioridad de poderío que tiene el Estado, su decisión no debe ser arbitraria, sino por el contrario, deberá de reflejar una decisión que se ajuste a los parámetros de justicia.

Es muy difícil concentrar en estas pocas cuartillas, la problemática que conlleva el ejercicio del poder dentro del Estado mexicano. La intención de su servidor radicó en hacer unos señalamientos respecto a lo complejo que resulta desentrañar las disposiciones contenidas en el pacto federal, pero que sobre todo, al valorar la asignación de funciones respecto al ámbito competencial de la federación, las entidades federativas y el municipio, así como aquellas que derivan de la forma de gobierno, están impregnadas de una inercia natural que los lleva al fortalecimiento del gobierno federal.

Esta concentración de poder, ha propiciado un desequilibrio en la concepción misma de la teoría de Montesquieu de la distribución del poder. El no prever los resultados deseados en el futuro inmediato, podría generar una crisis de estado con consecuencias catastróficas sobre nuestra nación. Es necesario hacer un ajuste respecto a la forma como se ejerce el poder, de tal forma que se establezca un escenario de equilibrio entre los diferentes órganos que lo ejercen en un Estado, y por lo consecuente, en la delimitación de competencias que deberán ser exclusivas de las entidades federativas y aquellas que convendrá encargar al municipio.

La experiencia en la tradición mexicana nos ha arrojado como consecuencia que, las entidades federativas siguen quedando al margen de las decisiones trascendentales dentro del desarrollo del Estado. Es importante valorar el esquema propuesto y desarrollado hasta el día de hoy, debido a que si dejamos pasar este momento, dejaremos que las cosas se mantengan en la inercia que se ha ejercido, perdiendo la oportunidad de realizar cualquier ajuste que pueda cambiar el rumbo hacia un esquema mejor para la ciudadanía.

Sólo confrontando el modelo en estos momentos, será posible determinar si la existencia de un bicameralismo, la delimitación de competencias entre los tres órdenes de gobierno y otras cuestiones que sustentan el modelo, por citar algunos de los temas que debemos analizar, en este sentido, entendemos que no será una tarea fácil, pero sin dudarlo creo que es el momento para enfocarnos en estos temas.

El nuevo esquema previsto por el Estado mexicano para la protección de los Derechos Humanos, es de una mayor complejidad. Si bien es cierto que, se posiciona como una nación 
progresista y moderna en el ámbito internacional, al consagrar y elevar al máximo nivel posible, el garantizar el ejercicio de las libertades de quienes habitamos esta nación, y que propicia la alineación de facultades de todos los órdenes y niveles de gobierno en esta materia, lo cierto es también que, cumplir con las mismas no va a ser una tarea sencilla.

Ante este escenario, es conveniente que los integrantes de los poderes judiciales de esta nación, sean quienes se encarguen de sentar las bases para la debida aplicación de las normas jurídicas internas y externas relativas a la materia de Derechos Humanos, es decir, se requiere de la colaboración tanto de la Federación como de las entidades federativas para dar cumplimiento a esta nueva realidad, de tal forma que nuestra nación, lleve a cabo las medidas que le permitan reivindicarse como una de las naciones más avanzadas en la protección y defensa de los derechos humanos.

Si bien es cierto que, ya existen evidencias de la buena voluntad de quienes desempeñan una función pública tan relevante como lo es, la de impartir justicia en una sociedad, se requiere de un esfuerzo mayor que permita clarificar y expandir en la mayor cantidad de los órganos jurisdiccionales del país, debido a que, debemos recordar que la reforma constitucional en materia de derechos humanos se implementó desde el año 2011.

La sociedad mexicana del siglo XXI, necesita de que el Estado genere las condiciones para un desarrollo individual adecuado, pero que también atienda a los sectores más desprotegidos, a través de políticas que disminuyan los índices de desigualdad que puedan existir en nuestra sociedad. La formación en los individuos de una educación básica, pueda generar las bases para la actividad laboral se desarrolle de manera adecuada, y propiciar lo indispensable para el sostenimiento de una familia, y hasta la solución de los problemas de salud.

A pesar de los esfuerzos institucionales del Estado mexicano por reforzar la protección inclusive de los derechos humanos con la reciente reforma constitucional en materia de Amparo y Derechos Humanos, y que constituye sin dudarlo un gran paso en la adecuación del marco normativo, sus efectos se ven reducidos cuando la tradición social es diferente en la formación de los individuos, y se convierten en esfuerzos con un escaso impacto en los resultados.

Entendemos que, los órganos del Estado ejercen un papel trascendental en dos aspectos fundamentales; el primero, la regulación del poder, con el objetivo primordial de mantener el equilibrio de los órganos que ejercen el poder y evitar el abuso en perjuicio no sólo de los demás entes, sino de la sociedad; y el segundo, consistente en garantizar la vigencia de los derechos humanos, es decir de las libertades del individuo, lo normal, es que durante el ejercicio de la función pública es que puedan cometerse errores, pero la historia se encargará de registrarlos para evitar caer nuevamente en ellos, pero lo normal, también debe ser que poco a poco nuestra sociedad continúe evolucionando hacia esa sociedad moderna en donde todos vivamos en paz y orden.

En este sentido, es conveniente que, el compromiso del Estado mexicano con la transparencia sea real, si continuamos bajo el camino de la discrecionalidad en el ejercicio del poder, lo único que propiciaremos es la ausencia de un control real que supervise el gasto público. De nada sirven las reformas estructurales impulsadas en la actual administración, si éstas no se traducen en resultados palpables, visibles para todos los mexicanos.

En el caso de los derechos sociales, la ecuación es sencilla, necesitamos transparentar el gasto público, sólo así podremos saber si las cosas se están haciendo bien, de no hacerlo, 
perdemos la oportunidad histórica de corregir los errores que se han cometido, resultando condenados a seguir repitiéndolos en el futuro inmediato.

Entendemos que, no es una tarea sencilla, pero el no hacerlo en el presente, conlleva una gran responsabilidad para con quienes heredaremos esta gran nación, en mi caso, desde mi actividad, siento la obligación de señalar las carencias que se tienen en la nación, porque mientras se siga bajo esta vía, al final, entenderemos que unos cuantos, sólo unos cuantos, han mantenido el control del Estado en su beneficio personal, traicionando con ello a quienes confiaron en ellos para que nos gobiernen.

Debemos recordar que, en democracia, no interesa la decisión por sí misma, sino las razones que le den sustento a la misma, porque si no encontramos motivos suficientes y adecuados que sean válidos para justificar la condición que tenemos, debemos aceptar en consecuencia que, somos dignos de compararnos con los sistemas totalitarios, sólo para dejar ver el grado de barbarie que como nación estamos dispuestos a realizar.

El ejemplo a seguir esta marcado, las acciones a implementar en el medio y largo plazo, si se hacen en este rubro, contribuirán sin dudarlo al fortalecimiento de la democracia, y con esto, a garantizar la aplicación del principio de justicia y el respeto de los derechos humanos, con miras a lograr una nación más prospera, en donde el goce los derechos sociales inclusive, alcancen el Estado de bienestar que desea toda nación civilizada en el mundo moderno.

IX. FUENTES

BIBLIOGRÁFICAS

ALEXY, Robert, Teoría de los Derechos Fundamentales, ed. Centro de Estudios Políticos y Constitucionales, Madrid 1993.

ABRAMOVICH, Víctor y Courtis Christian, en Los derechos sociales como derechos exigibles, ed. Trotta, segunda edición, Madrid, 2004, p. 19.

BERETTONI, Arleri, L'Ordenamentoed il controllo della spesapubblica in Francia, ed. Giuffré, Milano, 1967.

CARBONELL, Miguel, Los derechos fundamentales en México, Cuarta Edición, ed. UNAMCNDH, México 2011.

Miguel, Las obligaciones del Estado en el artículo $1^{\circ}$ de la Constitución Mexicana y FERRER MAC-GREGOR, Eduardo, Interpretación conforme y control difuso de convencionalidad, ambas colaboraciones publicadas en la obra La reforma Constitucional en Derechos Humanos: un nuevo paradigma, Coordinada por Miguel Carbonell y Pedro Salazar, ed. IIJ-UNAM, México 2011, p. 358 y ss.

C. FABRE, Social Rights under the Constitution, ed. Oxford, 2000, p. 44 y ss.

CONTRERAS PELÁEZ, Derechos sociales: teoría e idelología, Madrid 1994, p. 21 y ss.

CHUBB, Basil, The Control of Public Expenditure. Financial Committees of the House of Commons, Clarendon Press, Oxford, 1952, p. 6.

DEVOLVE, Pierre et Lesgullons, Henry, Le contrôle parlamentaire sur la politique économique et budgétaire, Presses Universitaires de France, Paris, 1964, p. 10 y ss. 
DWORKIN, Ronald, Los Derechos en serio, editorial Ariel, Barcelona, 1984.

FERRAJOLI, Luigui, Los Fundamentos de los Derechos Fundamentales, editorial Trotta, Madrid, 2001.

G. H. J. Van Hoof, “The Legal Nature of Economic, Social and Cultural Rights: A Rebuttal of Some Traditional Views" en P. Alston y K. Tomâsevski (eds.) The Right of Food, Utrecht, 1984.

GONZÁLEZ DE LA VEGA, Rene, Justicia e ideología. Libro electrónico (2008) IIJ-UNAM, p. 1.

HAMILTON, et al, Federalist, New American Library Press, New York, 2003.

HARRIS, Joseph P., Congressional Control of Administration, Reprinted by Greenwood Press, Wesport, Connecticut, 1980, p. 4 y ss.

LOCKE, John, Ensayo sobre el gobierno civil, ed. Porrúa, México, 2003.

KELSEN, Hans, Foundations of Democracy, Ethics, LXVI (Escritos sobre la democracia y el socialismo), traducción de Juan Ruiz Manero, ed. Debate, Madrid, 1995, p. 207 y ss.

MONTESQUIEU, L'Esprit des Lois, ed. Granier, Paris, 1784 e-book by www.archive.org/ details/delespritdeloiromontgoog, consultado el 30 de marzo de 2014.

NIKKEN, Pedro, Estudios básicos de derechos humanos, t. I, Ed. Instituto Interamericano de derechos humanos, Primera edición San Jose, 1994, libro electrónico http://www. bibliojuridica.org/libros/libro.htm?l=1835 IIJ UNAM (2008) pp. 15 y ss.

NOHLEN, Dieter, El contexto hace la diferencia: reformas institucionales y el enfoque histórico empírico, IIJ UNAM y Tribunal Electoral del Poder Judicial de la Federación, México, 2003, pp. 136 y ss.

ORLANDO, Principii di Diritto Costituzionale, ed. Barbera, 5th ed., Firenze, 1909, p. 143.

PERELMAN Chaim, De la justicia, Centro de Estudios Filosóficos, UNAM, libro electrónico IIJ UNAM (2008), http://www.bibliojuridica.org/libros/libro.htm?l=453, Primera Edición en español 1964, pp. 43 y ss.

PÉREZ ROYO, Javier, "El Tribunal de Cuentas en la Constitución y en el proyecto de ley reguladora del mismo" en El Tribunal de Cuentas en España, Vol. II, Instituto de Estudios Fiscales, Madrid, 1982, p. 1145 y ss.

RAWLS, John, Teoría de la Justicia, ed. Fondo de Cultura Económica, México, 1995.

RECASENS SICHES, Luis, Panorama del pensamiento político en el siglo XX, ed. Porrúa, México, 1963, T. I, p. 63.

ROUSSEAU, Jean Jacques, El contrato social, ed. Porrúa, México, 2006.

R. Bin, "Diritti e fraintendimenti": Ragion Pratica,14, 200o, p. 14 y ss.

S. HOLMES y C.R. Sunstein, The Cost of Rights-Why Liberty Depends on Taxes, Nueva York- Londres, 1999. 
TOCQUEVILlE, Alexis, De la Démocratie en Amérique, La democracia en América, ed. Alianza Editorial, colección Política, primera edición, 2002.

VALLESPÍN PÉREZ, David, El modelo constitucional de juicio justo en el ámbito del proceso civil, Barcelona, 2002, p. 31.

WALKER, Wallace Earl, Changing Organizational Culture, Strategy, Structure and Professionalism in the U.S. General Accounting Office, The University of Tennessee Press, Knoxville, 1986.

HEMEROGRAFÍA

ARAGÓN REYES, Manuel, "Sistema parlamentario, sistema presidencialista y dinámica entre los poderes del Estado. Análisis comparado" en Parlamento y Control del Gobierno. V Jornadas de la Asociación Española de Letrados de Parlamentos, coord. Francesc Pau I Vall, ed. Aranzadi, Pamplona, 1998, p. 30.

BALLS, Herbert R., “The Public Accounts Committee”, en Canadian Public Administration, V. 6, 1963, p. 15 .

CARPIZO, Jorge, Los Derechos Humanos: naturaleza, denominación y características, en Revista Mexicana de Derecho Constitucional, número 25 julio-diciembre 2011, p. 4 y ss.

COEN, F., "Declino del parlamento ed organizzacione di nuovi centri di potere" en Democrazia e diritto, enero-marzo, 1963.

EIDE, A., "Future Protection of Economic and Social Rights in Europe" en A. Bloed et al (eds.) Monitoring Human Rights in Europe: Comparing International Procedures and Mechanisms, Dordrecht-Boston-Londres, 1993.

ESPERÓN LÁZARO, José Antonio, "El Tribunal de Cuentas de la Comunidad Económica Europea ante los dos modelos de control externo: Francia y Gran Bretaña" en $A A V V$ El Tribunal de Cuentas de las Comunidades Europeas y los Tribunales de Cuentas de los países miembros: competencias y relaciones, Encuentro Internacional, Tribunal de Cuentas, Madrid, 1989, p. 209.

FORSTHOFF, Ernst, "Problemas constitucionales del Estado social” y "Concepto y esencia del Estado Social de Derecho" en El Estado Social, ed. Centro de Estudios Constituconales, Madrid, 1986.

GARCÍA MORILLO, Joaquín, "El parlamento ante las nuevas realidades” en Corts, Anuario de Derecho Parlamentario, número 4, 1997, p. 141 y ss.

GARRETÓN MERINO, "La sociedad civil como agente de promoción de los derechos económicos, sociales y culturales" en IIDH, estudios básicos de derechos humanos $V$, San José de Costa Rica, 1996, p. 59.

KAREL VASAK, "Human Rights: A Thirty-Year Struggle: the Sustained Efforts to give Force of law to the Universal Declaration of Human Rights", UNESCO Courier 30:11, 
Paris: United Nations Educational, Scientific, and Cultural Organization, November 1977.

P. ALSTON, "No Night to Complain About Being Poor: The Need for an Optional Protocol to the Economic Rights Covenant" en A. Eide y J. Helgesen (eds.) The Future of Human Rights Protection in a Changing World, 1991. 